\title{
A Review on SCR System for NOx Reduction in Diesel Engine
}

\author{
H.S. Latha*, K.V. Prakash, M. Veerangouda, Devanand Maski and K.T. Ramappa \\ Department of Farm Machinery and Power Engineering, \\ University of Agricultural Sciences, Raichur-584 104, India
}

*Corresponding author

\section{Keywords}

Diesel engine, SCR system, Nitrogen oxide, Reducing agent, Catalyst

Article Info

Accepted:

12 March 2019

Available Online:

10 April 2019
A B S T R A C T

The energy requirement has increased exponentially over the past decades due to industrialization and the changes of subsequent lifestyle. Almost $90 \%$ of the present energy source is based on the combustion of fossil fuels. Diesel engines are considered the most ideal power generators in transportation and industrial sectors owing to their fuel economy and efficiency. However, they suffer from the disadvantages of exhaust pollutants particularly oxides of nitrogen $\left(\mathrm{NO}_{\mathrm{x}}\right)$, which are facing increasingly stringent emission regulations which led to the search for alternative technologies. The technologies that allow for the highest $\mathrm{NO}_{\mathrm{x}}$ reduction are EGR (Exhaust gas recirculation), $\mathrm{NO}_{\mathrm{x}}$ absorbers, lean $\mathrm{NO}_{x}$ catalyst system and SCR (Selective catalytic reduction). Selective Catalytic Reduction system (SCR) is an advanced active emissions control technology converts nitrogen oxides $\left(\mathrm{NO}_{\mathrm{x}}\right)$ with the aid of catalyst into diatomic nitrogen $\left(\mathrm{N}_{2}\right)$, and water $\left(\mathrm{H}_{2} \mathrm{O}\right)$. To take place the conversion reactions, a reducing agent is need, which is usually a solution of urea $(32.5 \%)$ and high purity water (distilled water) known as AdBlue. AdBlue is decomposed into ammonia and water vapour, and then decomposed ammonia is adsorbed on the catalyst substrate then adsorbed ammonia reacts with oxides of nitrogen and reduced into eco-friendly nitrogen and water vapour.

\section{Introduction}

The energy requirement has increased exponentially over the past decades due to industrialization and the changes of subsequent lifestyle. Most of this energy is generated from fossil fuels such as coal, natural gas, gasoline, and diesel (Camarillo et al., 2013). Almost $90 \%$ of the present energy source is based on the combustion of fossil fuels and biomass. In the last few decades, the environmental effects of pollutant emission from combustion sources have becoming increasingly serious. Diesel engines are widely used in many areas like automobiles, locomotives marine engines power generations etc.., due to its high power output and thermal efficiency (Sounak Roy et al., 2009). Even though the diesel engines give more benefits, the human discomfort caused by pollutant emission of these engines has to be considered (Rahimpour et al., 2012). The major pollutant emissions of the diesel engines are $\mathrm{NO}_{\mathrm{x}}$, particulate matters, smoke 
and soot particles. Although all other emissions, $\mathrm{NO}_{\mathrm{x}}$ is one of the most important emission from diesel engines. It plays an important role in the atmospheric ozone destruction and global warming. It is also most precursors to the photochemical smog (Ziang et al., 2011). Component of smog irritate eyes and throat, stir up asthmatic attacks, decrease visibility and damages plants and materials as well. By dissolving with water vapor $\mathrm{NO}_{\mathrm{x}}$ from acid rain which has direct and indirect effects both on human and plants (Fujishim et al., 2013).

Because of these disadvantages diesel engines are facing increasingly stringent emission regulations which led to the search for alternative technologies. The technologies that allow for the highest $\mathrm{NO}_{\mathrm{x}}$ reduction are EGR, $\mathrm{NO}_{\mathrm{x}}$ absorbers, lean $\mathrm{NO}_{\mathrm{x}}$ catalyst system and SCR. Lean $\mathrm{NO}_{\mathrm{x}}$ catalyst system are not suitable for mobile vehicles due to their narrow temperature window and poor thermal conductivity. $\mathrm{NO}_{\mathrm{x}}$ absorbers high operating temperature window, but highly sensitive to sulphur poisoning. EGR is currently being used in production vehicles and has been shown to be reliable and effective but it is only able to reduce $\mathrm{NO}_{\mathrm{x}}$ emission by $50 \%$. SCR allows for greater than $90 \%$ reduction of $\mathrm{NO}_{\mathrm{x}}$ emission when compared to these technologies (King, 2007).

Selective Catalytic Reduction (SCR) is an advanced active emissions control technology converts nitrogen oxides referred to as $\mathrm{NO}_{\mathrm{x}}$ with the aid of a catalyst into diatomic nitrogen $\left(\mathrm{N}_{2}\right)$, and water $\left(\mathrm{H}_{2} \mathrm{O}\right)$. To take place the conversion reactions, a reducing agent is need, which is usually a solution of urea $(32.5 \%)$ and high purity water (distilled water) known as AdBlue, but other solutions such as anhydrous ammonia, aqueous ammonia which are sprayed into the smoke flow or exhaust gas and are absorbed into the catalyst are known (Balogh et al., 2011). SCR technology was first applied in thermal power plants in Japan in the late 1970s, followed by widespread application in Europe since the mid-1980s. In the USA, SCR systems were introduced for gas turbines in the 1990s, with a growing number of installations for $\mathrm{NO}_{\mathrm{x}}$ control from coal-fired power plants. Since mid-2000s, urea-SCR technology has been also adopted for mobile diesel engines (www.dieselnet.com).

\section{SCR technology}

Since mid-2000s, urea-SCR technology has been also adopted for mobile diesel engines. The mobile engine application required overcoming several problems related to the urea dosing technology, catalysts optimization, as well as urea infrastructure. Some regulatory authorities notably the US EPA were initially skeptical about the SCR compliance path with emission standards, both in terms of ensuring that the reductant (urea) is available together with diesel fuel throughout the nationwide distribution network, and that it is always timely replenished by vehicle operators. Ultimately, SCR proved to be a more robust emission technology than the main alternative option, $\mathrm{NO}_{\mathrm{x}}$ adsorbers, and has been widely used in all types of mobile diesel engines.

Urea-SCR has been selected by a number of manufacturers as the technology of choice for meeting the Euro V (2008) and the JP 2005 NOx limits both equal to $2 \mathrm{~g} / \mathrm{kWh}$ for heavyduty truck and bus engines. First commercial diesel truck applications were launched in November 2004 by Nissan Diesel in Japan and in early 2005 by Daimler (Daimler Chrysler at the time) in Europe. In the United States, SCR systems were introduced by most engine manufacturers in 2010, to meet the US EPA $\mathrm{NO}_{\mathrm{x}}$ limit of $0.2 \mathrm{~g} / \mathrm{bhp}$-hr for heavy-duty engines. In light-duty vehicles, SCR was introduced in some US EPA Tier 2 vehicles, 
while others used $\mathrm{NO}_{\mathrm{x}}$ adsorbers. By about 2012-2015, most of the Tier 2 vehicles with $\mathrm{NO}_{\mathrm{x}}$ adsorbers have been converted to ureaSCR. In Europe, SCR was introduced on certain Euro 5 models, with a much wider application of the technology in Euro 6 vehicles. SCR was introduced in nonroad diesel engines to meet the US Tier $4 \mathrm{i} / \mathrm{EU}$ Stage IIIB emission standards (King, 2009).

\section{SCR operation principle}

The $\mathrm{NO}_{\mathrm{x}}$ reduction reaction takes place as the exhaust gases pass through the catalyst chamber converter and thus converts the nitrogen oxides contained in the exhaust gas into water vapour and nitrogen. Before entering the catalyst chamber the ammonia or other reductant (such as urea), is injected and mixed with the gases.

\section{SCR-reductant}

SCR technology permits the $\mathrm{NO}_{\mathrm{x}}$ reduction reaction to take place in an oxidising atmosphere. It is called selective because the catalytic reduction of $\mathrm{NO}_{\mathrm{x}}$ with ammonia $\left(\mathrm{NH}_{3}\right)$, urea, monomethylamine, dimethylamine, trymethylamine, cyanuric acid, carbamates, ammonium carbonate, ammonium bicarbonate, etc.. as a reductant occurs preferentially to oxidation of $\mathrm{NH}_{3}$ with oxygen with oxides of nitrogen (Jiang, 2010).

SCR is a process for reducing the concentration of $\mathrm{NO}_{\mathrm{x}}$ from the combustion exhaust, which involves the injection of aqueous solution of urea in the tail pipe of a four stroke, constant speed DI diesel engine. Ammonia has been ruled out as a reducing agent, due toxicity and handling issues. So urea has been selected for reductant of choice for most applications, stored on board in an aqueous solution. To overcome the difficulties associated with pure ammonia, urea is selected. Urea can be hydrolysed and decomposed to generate ammonia. An injected aqueous solution of urea solution is decomposed into ammonia and water vapour, and then decomposed ammonia reacts with oxides of nitrogen and reduced into ecofriendly nitrogen and water vapour (Praveen and Natarajan, 2014).

Several reductants are currently used in SCR applications including Anhydrous ammonia, Aqueous ammonia, Urea (AdBlue). Anhydrous ammonia extremely toxic and difficult to safely store, but needs no further conversion to operate within an SCR. Typically favoured by large industrial SCR operators. Aqueous ammonia must be vapourized in order to be used, but it is substantially safer to store and transport than anhydrous ammonia. Urea (AdBlue) is safest to store, but requires conversion to ammonia through thermal decomposition in order to be used as an effective reductant (King, 2007).

\section{SCR system}

SCR system consists of Diesel Exhaust Fluid (DEF) tank and pump, SCR Catalytic Converter, Control device.

Diesel Exhaust Fluid (DEF) tank and pump: Under the direction of the vehicle's onboard computer, DEF is delivered in precisely metered spray patterns into the exhaust stream just ahead of the SCR converter. SCR Catalytic Converter: This is where the conversion happens. Exhaust gases and an atomized mist of DEF enter the converter simultaneously. Together with the catalyst inside the converter, the mixture undergoes a chemical reaction that produces nitrogen gas and water vapour.

Control device: Exhaust gases are monitored via a sensor as they leave the SCR catalyst. Feedback is supplied to the main computer to alter the DEF flow if $\mathrm{NO}_{\mathrm{x}}$ levels fluctuate beyond acceptable parameters (King, 2007). 
Steps involved in $\mathrm{SCR} \mathrm{NO}_{\mathrm{x}}$ reduction process

The SCR $\mathrm{NO}_{\mathrm{x}}$ reduction process can be summarized as three major steps. In the first step, urea solution (AdBlue), as the source of the reductant $\left(\mathrm{NH}_{3}\right)$, is injected at the upstream of the catalyst and then is converted to $\mathrm{NH}_{3}$.

In the second step, the $\mathrm{NH}_{3}$ inside the catalyst is adsorbed on the catalyst substrate. The adsorbed $\mathrm{NH}_{3}$ can then catalytically react

1. AdBlue evaporation:

$\mathrm{NH}_{2}-\mathrm{CO}-\mathrm{NH}_{2}$ (liquid) $\rightarrow \mathrm{NH}_{2}-\mathrm{CO}-\mathrm{NH}_{2}+\mathrm{H}_{2} \mathrm{O}$,

2. Urea decomposition:

$\mathrm{NH}_{2}-\mathrm{CO}-\mathrm{NH}_{2} \rightarrow \mathrm{NH}_{3}+\mathrm{HNCO}$,

3. Isocyanic acid (HNCO) hydrolyzation:

$\mathrm{HNCO}+\mathrm{H}_{2} \mathrm{O} \rightarrow \mathrm{NH}_{3}+\mathrm{CO}_{2}$

For the AdBlue evaporation process, it has been reported that the reaction is mainly affected by the spatial droplet size and temperature (Kim and Ha, 2014), such that the reaction rate of this process can vary between different AdBlue injector designs and engine operating conditions. With evaporated AdBlue (urea), equal mole ammonia and isocyanic acid can be generated through the decomposition process. Recent studies have pointed out that this process strongly depends on temperature. The reaction generally starts from $200^{\circ} \mathrm{C}$ and reaches a maximum reaction rate around $350^{\circ}$ $\mathrm{C}$ (Hsieh and Wang, 2010). When the exhaust gas temperature is less than $200^{\circ} \mathrm{C}$, the urea decomposition reaction can generate byproducts such as cyanuric acid, biuret, melamine, ammelide and ammeline as deposits on pipe wall (Schaber et al., 2004), which are hard to be removed and are highly undesired. To avoid this problem, urea injection generally starts when exhaust temperature is higher than $200^{\circ} \mathrm{C}$ and double- with $\mathrm{NO}_{\mathrm{x}}$ and convert them to nitrogen molecules and water, which is the third step.

\section{AdBlue to $\mathrm{NH}_{3}$}

For SCR systems in vehicle applications, $32.5 \%$ aqueous urea solution (AdBlue) has been specified as the source of ammonia. AdBlue is converted to ammonia mainly by three steps: evaporation, decomposition, and hydrolyzation (Piazzesi et al., 2006) as shown in Eq. (1), Eq. (2), and Eq. (3).

wall design to avoid heat conduction from exhaust gas to outside environment is often used by the exhaust pipe between AdBlue injector and SCR catalyst. Hydrolyzation is another process which can convert the isocyanic acid (HNCO) generated from urea decomposition to equal mole ammonia and $\mathrm{CO}_{2}$. This reaction, on the other hand, is very inactive under temperature of $400^{\circ} \mathrm{C}$. However, with the presence of catalyst such as zeolite based SCR catalyst, this reaction becomes very fast and studies have reported that the reaction rate is 2 orders of magnitude faster than the SCR De- $\mathrm{NO}_{\mathrm{x}}$ reaction rate. In other words, complete conversion of HNCO to $\mathrm{NH}_{3}$ is possible at the upstream part of the SCR catalyst.

\section{$\mathrm{NH}_{3}$ adsorption/desorption}

The ammonia adsorption process is a twoway reaction which can be explained by the following equation. 
$\mathrm{NH}_{3}+\theta$ free $\leftrightarrow \mathrm{NH}_{3} *,(4)$

Where $\theta$ free represents the free substrate site of the SCR catalyst and $\mathrm{NH}_{3}$ * represents the ammonia which has been adsorbed on the SCR substrate. An important variable which strongly relates to ammonia adsorption/desorption reactions is the SCR catalyst storage ammonia capacity, which has been reported to be temperature related.

The ammonia adsorption and desorption rates are related to the amount of free catalyst sites $\theta$ free, which can be directly affected by the ammonia storage capacity. If the ammonia storage capacity is not correctly considered in SCR control or SCR modeling, unexpected ammonia slip can be observed (King, 2007).

\section{$\mathrm{NO}_{\mathrm{x}}$ conversion}

The major SCR NOx reductions processes are listed below.

$$
\begin{aligned}
& 4 \mathrm{NH}_{3}+4 \mathrm{NO}+\mathrm{O}_{2} \rightarrow 4 \mathrm{~N}_{2}+6 \mathrm{H}_{2} \mathrm{O} \\
& 2 \mathrm{NH}_{3}+\mathrm{NO}+\mathrm{NO}_{2} \rightarrow 2 \mathrm{~N}_{2}+3 \mathrm{H}_{2} \mathrm{O} \\
& 4 \mathrm{NH}_{3}+3 \mathrm{NO}_{2} \rightarrow 3.5 \mathrm{~N}_{2}+6 \mathrm{H}_{2} \mathrm{O}
\end{aligned}
$$

The first reaction in Eq. (5) is generally known as "standard" SCR. In typical exhaust gases, NOx is composed mainly of $\mathrm{NO}$ $(>90 \%)$, which reacts with ammonia according to the standard SCR reaction. Under the usual operating conditions of diesel exhaust, the standard SCR reaction has a high potential of $\mathrm{NO}_{\mathrm{x}}$ reduction at temperatures above $300^{\circ} \mathrm{C}$. A major challenge in developing the urea-based SCR process for automotive applications is the enhancement of the SCR activity at lower temperatures. In addition to measures aiming at increasing the volumetric activity of the SCR catalyst itself, use of the "fast SCR" reaction in Eq. (6) is another possibility for enhancing SCR efficiency, especially at low temperatures (Madia et al., 2002). In fact, below $300^{\circ} \mathrm{C}$, the fast SCR reaction utilizing an equimolar mixture of $\mathrm{NO}$ and $\mathrm{NO}_{2}$ proceeds much more rapidly than the standard SCR reaction with pure NO (Koebel et al., 2001). However, reaction (7) is much slower than the fast SCR reaction in Eq. (6) and still slower than the standard SCR reaction in Eq. (5) (Madia et al., 2002).

\section{Undesired reactions}

Undesired reactions of Eq. (8) and (9) only occur if $\mathrm{NO}_{2}$ levels are high in exhaust stream above $50 \%$. Undesired Reaction of Eq. (10) will occur at temperature about $450^{\circ} \mathrm{C}$; in this reaction ammonia reacts with oxygen to form $\mathrm{N}_{2} \mathrm{O}$. Oxygen is abundant in diesel exhaust, undesirable reactions with oxygen can occur. Reactions of Eq. (11) and (12) are undesirable reactions with oxygen that results in water, nitrogen and NO. Reaction of Eq. (13) results in the formation of ammonium nitrate.

Ammonium nitrate only forms at temperature below $200^{\circ} \mathrm{C}$. Ammonium nitrate will deposit on active material of the catalyst leading to temporary deactivation (Koebel et al., 2002). At temperature below $200^{\circ} \mathrm{C}$ reactions of Eq. (14) and (15) can occurs which creates ammonium sulphates. These sulphates will deposit on the catalyst causing deactivation (Lepperhoff and Schommers, 1988). Regenerating the catalyst at temperature above $500^{\circ} \mathrm{C}$ removes the sulfur deposits and restores the catalyst activity (King, 2007).

$$
\begin{aligned}
& 8 \mathrm{NO}_{2}+6 \mathrm{NH}_{3} \rightarrow 7 \mathrm{~N}_{2} \mathrm{O}+9 \mathrm{H}_{2} \mathrm{O} \\
& \mathrm{NO}_{2}+4 \mathrm{NH}_{3}+\mathrm{O}_{2} \rightarrow 4 \mathrm{~N}_{2} \mathrm{O}+6 \mathrm{H}_{2} \mathrm{O} \\
& 2 \mathrm{NH}_{3}+2 \mathrm{O}_{2} \rightarrow \mathrm{N}_{2} \mathrm{O}+3 \mathrm{H}_{2} \mathrm{O} \\
& 4 \mathrm{NH}_{3}+3 \mathrm{O}_{2} \rightarrow 2 \mathrm{~N}_{2}+6 \mathrm{H}_{2} \mathrm{O} \\
& 4 \mathrm{NH}_{3}+5 \mathrm{O}_{2} \rightarrow 4 \mathrm{NO}+6 \mathrm{H}_{2} \mathrm{O} \\
& 2 \mathrm{NH}_{3}+2 \mathrm{NO}_{2}+\mathrm{H}_{2} \mathrm{O} \rightarrow \mathrm{NH}_{4} \mathrm{NO}_{3}+\mathrm{NH}_{4} \mathrm{NO}_{2} \\
& (13) \\
& \mathrm{NH}_{3}+\mathrm{SO}_{3}+\mathrm{H}_{2} \mathrm{O} \rightarrow \mathrm{NH}_{4} \mathrm{HSO}_{4}, \\
& 2 \mathrm{NH}_{3}+\mathrm{SO}_{3}+\mathrm{H}_{2} \mathrm{O} \rightarrow\left(\mathrm{NH}_{4}\right)_{2} \mathrm{SO}_{4}
\end{aligned}
$$




\section{SCR catalyst}

Without catalyst, acceptable reduction of $\mathrm{NO}_{\mathrm{x}}$ using ammonia occurs at temperatures in the range of $800-900^{\circ} \mathrm{C}$. Above $900^{\circ} \mathrm{C}$, ammonia oxidises into $\mathrm{NO}_{\mathrm{x}}$. Using catalyst, the reaction of ammonia and $\mathrm{NO}_{\mathrm{x}}$ can occurs at temperature between $150-550^{\circ} \mathrm{C}$. The two types of structures used for SCR catalysts are supported catalyst and unsupported catalyst. A catalyst with a supported structure has three layers, the substrate, porous oxide support and catalytic material. The substrate of the catalyst is usually monolith honey comb structure made of ceramic or metal. The porous oxide support layer is made of materials that have high surface area. The increased surface area allows catalyst to be more active. Materials used for porous oxide support are zeolite or titania. Third layer is catalytic material. It consists of transition metals such as copper, iron, platinum or other metals. In Unsupported catalyst structure, the catalytic material and supporting material are mixed together. The mixture is then extruded into honeycomb shaped catalyst. Example; an unsupported vanadia catalyst is extruded from a mix of $\mathrm{TiO}_{2}, \mathrm{WO}_{3}$ and $\mathrm{V}_{2} \mathrm{O}$, siliconaluminates and glass fibers (www.dieselnet.com).

\section{Ammonia slip}

Ammonia emissions that are emitted from an SCR system are referred to as Ammonia slip. An imperfect control strategy that over injects urea or deactivation of the SCR catalyst can result in ammonia slip. Ammonia emissions are a poisonous gas which is harmful to plants and animals. Ammonia emitted into ambient air can combines with sulfuric acid and nitric acid to form ammonium sulfate and ammonium nitrate salts. SCR system normally designed to allow for maximum ammonia slip levels of 5-10 ppm. To prevent ammonia slip, an oxidation catalyst can be placed in downstream of the SCR catalyst. The catalyst is typically made up of platinum and aluminum oxide (King, 2007).

In conclusion, the SCR technology is the dominating $\mathrm{NO}_{\mathrm{x}}$ reduction technology to meet the current and future $\mathrm{NO}_{\mathrm{x}}$ emission regulations. SCR allows for greater reduction of $\mathrm{NO}_{\mathrm{x}}$ emission when compared to other technologies. SCR system converts nitrogen oxides from exhaust gas of diesel engine into eco-friendly nitrogen and water vapour. AdBlue is used as reductant in SCR system for $\mathrm{NO}_{\mathrm{x}}$ reduction. Using catalyst, the reaction of ammonia and $\mathrm{NO}_{\mathrm{x}}$ can occurs at temperature between $150-550^{\circ} \mathrm{C}$. The fast SCR reaction utilizes an equimolar mixture of $\mathrm{NO}$ and $\mathrm{NO}_{2}$ proceeds much more rapidly than the standard SCR reaction with NO. Ammonia emissions that are emitted from SCR system due to deactivation of catalyst is prevented by placing an oxidation catalyst in downstream of the SCR catalyst.

\section{References}

Balogh, R. M., Ionel, I., Stepan, D., Rabl, H. P. and Andreas, P., 2011, $\mathrm{NO}_{\mathrm{x}}$ reduction using selective catalytic reduction (SCR) system - $\alpha$ variation. Termotehnica, 38-42.

Giuseppe Madia, Manfred Koebel, Martin Elsener, and Alexander Wokaun, 2002, The Effect of an Oxidation Precatalyst on the $\mathrm{NO}_{\mathrm{x}}$ Reduction by Ammonia SCR. Ind. Eng. Chem. Res., 41: 35123517.

Hidekatsu Fujishima, Kenichi Takekoshi, Tomoyuki Kuroki, Keichi Otsuka, Masaaki Okubo and Atsushi Tanaka, 2013, Towards ideal $\mathrm{NO}_{\mathrm{x}}$ control technology for Bio-Oils and a gas multifuel boiler system using a plasmachemical hybrid process. Appl. Energ., 111: 394-400.

Hsieh, M. and Wang, J., 2010, Observer- 
based estimation of Diesel engine aftertreatment system $\mathrm{NO}$ and $\mathrm{NO}_{2}$ concentrations. Proceedings of the ASME Dynamic Systems and Control Conference.

Kim, J. Y., Ryu, S. H. and Ha, J. S., 2004, Numerical prediction on the characteristics of spray-induced mixing and thermal decomposition of urea solution in SCR system. Proceeding of ASME Internal Combustion Engine Division.

King, R. T., 2007, Design of a Selective Catalytic Reduction System to Reduce Nitrogen Oxide Emissions of the 2003 West Virginia University Future Truck.

Koebel, M., Elsener, M. and Madia, G., 2001, Reaction Pathways in the Selective Catalytic Reduction Process with NO and $\mathrm{NO}_{2}$ at Low Temperatures. Ind. Chem. Eng. Res., 40: 52.

Koebel, M., Madia, G. and Elsener, M., 2002, Selective catalytic reduction of $\mathrm{NO}$ and $\mathrm{NO}_{2}$ at low temperatures. Catal. Today, 73 (3/4): 239-247.

Lei Jiang, 2010, Unregulated emissions from a diesel engine equipped with vanadium-based urea-Selective Catalytic Reduction System catalyst. $J$. Environ. Sci., 22(4): 575-581.

Lepperhoff, G. and Schommers, J., 1988. Verhalten von SCR-Katalysatoren im dieselmotorischen Abgas, MTZ Motortechnische Zeitschrift, 49: 1.

Mary Kay Camarillo, William T. Stringfellow, Kyle A.Watson and Jereny S. Hanlon, 2013 Investigation of selective catalytic reduction for control of nitrogen oxides in full-scale dairy energy production. Appl. Energ., 106: 328-336.

Piazzesi, G., Devadas, M., Krocher, O., Elsener, M. and Wokaun, A., 2006, Isocyanic acid hydrolysis over $\mathrm{Fe}$ ZAM5 in urea SCR, Catal Communications, 7: 600-602.

Praveen, R. and Natarajan, S., 2014, Experimental study of selective catalytic reduction system on CI Engine fuelled with diesel-ethanol blend for $\mathrm{NO}_{\mathrm{x}}$ reduction with injection of urea solutions. Int. J. Eng. and Tech., 6 (2): 895-904.

Rahimpour, M. R., Dehnair M. R., Allahgholipour, F., Iranshahi, D. and Jokar, S. M., 2012, Assessment and comparison of different catalytic coupling exothermic and endothermic reactions - A review. Appl. Energ., 99: 496-512.

Schaber, P., Colson, J., Higgins, S., Thielen, D., Anspach, B. and Brauer, J., 2004 Thermal decomposition (pyrolysis) of urea in an open reaction vessel. Thermochimica Acta, 424: 131-142.

Sounak Roy, Hedge, M. S. and Giridhar Madras, 2009, Catalysis for $\mathrm{NO}_{\mathrm{x}}$ abatement - Review. Appl. Energ., 86: 2283-2297.

www.dieselnet.com

Zengying ziang, Xiaoqian Ma, Hai Lin and Yuting Tang, 2011, The Energy Consumption and Environmental impacts of SCR technology in china. Appl. Energ., 88: 1120-1129.

\section{How to cite this article:}

Latha, H.S., K.V. Prakash, M. Veerangouda, Devanand Maski and Ramappa, K.T. 2019. A Review on SCR System for NOx Reduction in Diesel Engine. Int.J.Curr.Microbiol.App.Sci. 8(04): 1553-1559. doi: https://doi.org/10.20546/ijcmas.2019.804.180 